\title{
6 \\ El gobierno de las Sociedades Cooperativas
}

\author{
Yaiza Juanes Sobradillo / Zuriñe Mazorriaga Manuel \\ Universidad de Deusto
}

\begin{abstract}
Sumario: A) Introducción y objetivos. 1. Introducción. 2. Objetivos.-B) Definición y antecedentes. 1. Definición. 2. Antecedentes.-C) Ley Vasca de Cooperativas. 1. Consideraciones previas. 2. Principios del cooperativismo. 3. Organos Sociales de la Sociedad Cooperativa. 3. 1. Asamblea General. a) Competencias. b) Convocatoria de la Asamblea. c) Funcionamiento. d) Derecho de voto y representación. e) Adopción de acuerdos. f) Impugnación de acuerdos. 3.2. Consejo Rector. a) Competencias. b) Funcionamiento. c) Adopción de acuerdos. d) Responsabilidad. e) Impugnación de acuerdos.-D) Ley de Cooperativas. 1. Consideraciones previas. 2. Organos Sociales de la Sociedad Cooperativa. 2.1. Asamblea General. a) Competencias. b) Convocatoria de la Asamblea. c) Funcionamiento. d) Derecho de voto y representación. e) Adopción de acuerdos. f) Impugnación de acuerdos. 2.2. El Consejo Rector. a) Competencias. b) Funcionamiento. c) Adopción de acuerdos. d) Responsabilidad. e) Impugnación de acuerdos. 2.3. La Intervención.-E) Estatuto de la Sociedad Cooperativa Europea. 1. Consideraciones previas. 2. Organos sociales de las Sociedades Cooperativas Europeas. 2.1. Asamblea General. a) Competencias. b) Convocatoria y funciones. c) Derecho de voto y representación. d) Adopción de acuerdos. 2.2. Sistema Dual. Organos de Dirección y Control. a) Competencias. b) Convocatoria. 2.3. Sistema monista. Organo de Administración. a) Funciones y designación de sus miembros. b) Periodicidad de las reuniones y derecho a la información. c) Presidencia y convocatoria. 2.4. Normas comunes a los sistemas dual y monista (artículos del 45 al 51 de SCE ).-F) Conclusión.
\end{abstract}

\section{A) INTRODUCCION Y OBJETIVOS}

\section{Introducción}

Durante el régimen franquista primaba un factor restrictivo importante dentro del sector privado y respecto al ámbito de la empresa, lo que aportaba una falta de sentido económico empresarial. Esa falta 
de cultura empresarial se debía, pues, a la inexistencia de un clima adecuado para el fomento de iniciativas empresariales y de la actividad mercantil. Se asentaba en un régimen de privilegios en el que la falta de proyectos de asociación y de gestión resultaban evidentes.

A partir de 1978, la democracia ha sido el marco, que ha permitido, que tanto la sociedad como la economía hayan prosperado de una forma notable $y$, a su vez, el establecimiento del principio de libertad ha ayudado a potenciar, asimismo, la actividad individual.

Así pues, el artículo 1 de la Constitución Española (en adelante CE) indica que «España se constituye en un Estado social y democrático de derecho, que propugna como valores superiores de su ordenamiento jurídico la libertad, la justicia, la igualdad y el pluralismo político» y sobre esta base, señala el artículo 129 CE, que «los poderes públicos promoverán eficazmente las diversas formas de participación en la empresa y fomentarán, mediante una legislación adecuada, las sociedades cooperativas», reafirmando con ello la actual inexistencia del anterior déficit de la cultura empresarial.

\section{Objetivos}

Con el presente trabajo se pretende exponer la «legislación adecuada de las sociedades mercantiles» a la que se refiere el artículo 129 CE, profundizando en el análisis de los órganos de gestión y control sobre la base de la Ley General y Vasca de Cooperativas y el Estatuto Europeo para Sociedades Cooperativas, exponiendo, en su caso, posteriormente, una posible modificación de dichos órganos.

\section{B) DEFINICION Y ANTECEDENTES}

\section{Definición}

La cooperativa es una sociedad que tiene por objeto el ejercicio en común de un negocio o industria en servicio directo de los socios. Son aquellas compañías que asocian a personas físicas para desarrollar una actividad, cuyo objeto es proporcionar puestos de trabajo a los socios para producir en común bienes o servicios para vender a terceros.

Por medio de la cooperativa se intenta suprimir el beneficio de los intermediarios y atribuírselo a los socios. Su finalidad, por tanto, 
no estriba en la especulación, sino en lograr la protección de sus miembros.

La forma jurídica adoptada comúnmente por las cooperativas es la de las sociedades por acciones, siendo su órgano soberano la Asamblea General de socios.

\section{Antecedentes}

En los siglos XVIII y XIX surgió un gran movimiento cooperativo que tuvo concreciones históricas importantes. Adoptadas en un principio en los programas de los movimientos socialistas y anarquistas, fueron más tarde introducidas en otras manifestaciones ideológicas.

Este sistema procede de formas antiguas populares comunitarias que se han ido practicando en todas las culturas. En general, ante las necesidades económicas, todos los pueblos responden de una forma común con el fin de ser satisfechos. La necesidad, por tanto, es la base histórica del cooperativismo.

La base real, no obstante, se sitúa desde finales del s. XVIII con la Revolución Liberal de Francia. Dicho advenimiento liberal se produjo por las clases bajas que, ante la necesidad de agruparse por la supervivencia, establecieron el así llamado «Capitalismo Salvaje».

El cooperativismo, como sistema alternativo al Capitalismo Salvaje, es un sistema que necesitó de una ordenación. Así, Inglaterra comenzó por la ordenación jurídica cooperativa, a través de la «Industrial Act» (Ley societaria de 1852), cuyos precedentes fueron los Estatutos de una cooperativa concreta: la "Cooperativa de Rochdelt». Así pues, fueron considerados como precedente legislativo en distintas naciones europeas para el establecimiento de normas relativas a las cooperativas.

Concretamente en España, el cooperativismo fue considerado primeramente como un contrasistema del capitalismo. Este nuevo sistema tuvo un desarrollo paulatino:

- Primera Ley de Cooperativas:

Promulgada en 1931 fue la primera Ley sobre esta materia en el derecho interno. Técnicamente carecía de un sistema de gestión asambleario eficaz. 
- Cataluña:

Dado que esta Comunidad Autónoma disponía de competencia en materia cooperativa, el Estatuto catalán promulgó su propia Ley a este respecto en el año 1934.

-País Vasco:

Al igual que el caso anterior, también al País Vasco se le atribuía dicha competencia y elaboró así en 1938 un proyecto de Ley Vasca sobre Cooperativas, que no llegó a promulgarse.

- Cooperativismo de Mondragón:

En 1942 se promulgó una aplicación sindicalista de cooperativismo a través de la "Obra Sindical Cooperativa». El cooperativismo de Mondragón, pues, fue uno de los ejemplos más importantes, a que dio cobertura esta Ley.

-Constitucionalismo:

Llegada la promulgación de la Constitución de 1978 fue necesario promulgar una nueva legislación cooperativa dentro del libre mercado, al amparo del artículo 129, 2 CE: «los poderes públicos promoverán eficazmente las diversas formas de participación en la empresa y fomentarán, mediante una legislación adecuada, las sociedades cooperativas. También establecerán los medios que faciliten el acceso de trabajadores a la propiedad de los medios de producción».

\section{C) LEY VASCA DE COOPERATIVAS}

\section{Consideraciones previas}

Introductoriamente, no hay que olvidar el problema de la distribución de competencias que se planteó entre el Estado y las Comunidades Autónomas a la hora de establecer el tema de delegación de competencias en la Constitución de 1978. Era necesario determinar si la competencia cooperativa era exclusiva del Estado o si, por el contrario, como históricamente había sucedido, pertenecía a cada Comunidad. Se elaboraron así, una Ley General y cinco posibles Leyes Autonómicas en los territorios de Cataluña, Galicia, País Vasco, Navarra y 
Andalucía. La Ley Vasca de Cooperativas de 11 de febrero de 1982, se adelantó a la Ley General y al resto de las autonómicas. Se elaboraron, asimismo, la Ley de Cooperativas de las Comunidades Autónomas de Cataluña, Navarra y Andalucía.

El problema residía en que regía el criterio de extraterritorialidad, que consistía en la aplicación de la ley del domicilio social. Este problema fue resuelto por la Sentencia del Tribunal Constitucional de 29 de julio de 1983, que se pronunció con relación a la Ley Vasca de Cooperativas de 1982, al establecer la aplicación de la ley por el criterio del domicilio.

Así, la Comunidad Vasca, en base a las atribuciones conferidas por el Estatuto de Autonomía en vigor, desarrolló a partir de 1982 una legislación específica en materia de cooperativas, partiendo especialmente de la Ley Vasca de Cooperativas, aprobada por el Parlamento Vasco el 11 de febrero de 1982. Pero, dado que la realidad social es cambiante, abierta y dinámica, dicha Ley, que en su momento originó un paso adelante y una mejora evidente sobre la Legislación Cooperativa preexistente, puede y debe ser objeto de adaptación y mejora en años posteriores.

Así pues, el cooperativismo actual se ha enriquecido, con lo que debe adaptarse tanto a la evolución de sus realidades como a las exigencias de un mercado cada vez más competitivo y exigente. Todo ello debe reflejarse adecuadamente en una norma que pretenda regular las sociedades cooperativas y promover su desarrollo en el siglo XXI, tal como recomendó el propio Parlamento Vasco en su sesión del 9 de enero de 1992. Por eso el análisis posterior se basará en la Ley 4/1993 de 24 de junio de Cooperativas de Euskadi.

Por lo tanto, como bien dice el artículo 1, 1 de la Ley Vasca de Cooperativas (en adelante LVC) «la cooperativa es aquella sociedad que desarrolla una empresa que tiene por objeto prioritario la promoción de las actividades económicas y sociales de sus miembros y la satisfacción de sus necesidades con la participación activa de los mismos, observando los principios del cooperativismo y atendiendo a la comunidad de su entorno.»

La LVC de 11 de febrero de 1982 se adecuó a los principios constitucionales del sistema democrático. 


\section{Principios del cooperativismo}

Los principios cooperativos son por ley una fuente para resolver los conflictos de actos cooperativos internos. Estas sociedades deben observan los principios de cooperativismo, que la propia Ley reconoce son reglas de interpretación de derecho cooperativo. Tales principios pueden clasificarse de la siguiente manera:

a) Sociedades económicas mercantiles:

Desarrolla aquella actividad que realiza la empresa. Es decir, son sociedades de objeto empresarial, cuyo objeto preferente es la promoción de actividades económicas sociales. Así viene establecido en el artículo 1 de la Ley Vasca de Cooperativas.

b) Sociedad democrático personal:

La gestión y control de la cooperativa se establecen democráticamente, lo que supone que los gestores han de ser elegidos democráticamente por los socios, al igual que los órganos encargados del control. Este principio se ha consagrado en el artículo 35 de la Ley Vasca de Cooperativas con la expresión «un hombre, un voto», que sintetiza la actuación democrática de la cooperativa en cuanto asociación de personas, y no de capitales, regida por la equidad más que por la igualdad.

c) Sociedades no capitalistas:

Toda la distribución de la soberanía jurídico social y las facultades jurídicas, se producen por sistema no capitalista. Así, en relación con el principio anterior, esto se manifiesta en los siguientes elementos:

-en el voto

-en la distribución del beneficio, en proporción a las operaciones, servicios y actividades desarrolladas.

\section{Organos Sociales de la Sociedad Cooperativa}

La sociedad cooperativa tiene diferentes órganos entre los que se destaca un órgano deliberante (Asamblea General) y un órgano ejecutivo (Consejo Rector), siendo éstos los que llevan a cabo las funciones de gestión y control respectivamente. 
Dada la importancia de los órganos señalados se requiere hacer un examen más exhaustivo de los mismos.

\subsection{Asamblea General}

La Asamblea General es la reunión de los socios cooperadores y constituye el órgano supremo de expresión de la voluntad social en las materias atribuidas por la Ley y por los Estatutos de cada cooperativa. Sus acuerdos son de obligado cumplimiento para TODOS los socios, incluidos los disidentes y los no asistentes, sin perjuicio de su impugnación ante la jurisdicción competente.

La Asamblea es uno de los dos órganos facultados de la sociedad cooperativa. Se trata de un órgano deliberante con facultades propias. Así bien, determina el artículo 31, 1 LVC que «es la reunión de todos los socios, constituido para deliberar y tomar acuerdos en las materias propias de su competencia», y consecuentemente, sus acuerdos son obligatorios para TODOS los socios, sin excepción (artículo 31, 2 LVC).

\section{a) COMPETENCIAS}

Este órgano está dotado de facultades exclusivas con la intención de evitar que se convierta en órgano paralizador de la vida social de la empresa y no impida el ejercicio de facultades los órganos restantes. Por ello, dichas facultades están explícitamente recogidas en el artículo 31, 3 LVC.

Además, la Ley especifica una serie de temas en relación a los cuales, en todo caso y sin posibilidad de delegación, los acuerdos pertinentes deben ser adoptados por la Asamblea General. Salvo ese contenido, el órgano que absorbe las competencias restantes es el Organo Ejecutivo. Esto es a lo que se refiere el artículo 40 LVC al señalar que «los administradores son el órgano al que corresponde en exclusiva la gestión y representación de la cooperativa, y ejercen además todas las facultades que no estén expresamente reservadas por la Ley o los Estatutos a otros órganos sociales».

Así pues, en base al artículo 31, 3 LVC corresponde, con carácter mínimo y exclusivo y no delegable, a la Asamblea General la facultad de adoptar los acuerdos que se enumeran a continuación: 
- Nombramiento y revocación, por votación secreta, de los administradores, de los miembros de la Comisión de Vigilancia y de los Liquidadores, así como, en su caso, de los miembros del Comité de Recursos y de los miembros del Consejo Social, y ejercicio de la acción de responsabilidad contra los mismos, en resumen, el nombramiento por votación secreta de todos los componentes de los demás órganos sociales.

- Nombramiento y revocación, que sólo cabrá cuando exista justa causa de los auditores de cuentas, es decir, cuando en la sociedad exista Auditoría de Cuentas, sus componentes deberán ser elegidos y/ o revocados, por votación secreta a propuesta de los administradores.

- Examen de la gestión social, aprobación de las cuentas anuales y de la distribución de excedentes o imputación de pérdidas, es decir, la aprobación o censura de la contabilidad ordinaria anual y de los administradores.

- Establecimiento de nuevas aportaciones obligatorias, del interés que devengaran las aportaciones a capital y de las cuotas de ingreso o periódicas.

- Emisión de obligaciones, de títulos participativos o de participaciones especiales, se refiere a su aprobación o censura.

- Modificación de los Estatutos Sociales, cualquiera que sea su naturaleza.

- Constitución de cooperativas de segundo grado, corporaciones cooperativas y entidades similares, así como la adhesión y separación de las mismas. Esta facultad es delegable a los administradores, siempre que se haya acordado también en la Asamblea.

-Fusión, escisión, transformación y disolución de la sociedad.

- Toda decisión que suponga, según los Estatutos, una modificación sustancial en la estructura económica, organizativa o funcional de la cooperativa, es decir, decidirá sobre alteraciones sustanciales en el orden económico organizativo funcional, aunque no trascienda en la actividad e la compañía.

- Aprobación o modificación del reglamento interno de la cooperativa, se refiere a la aprobación de reglamentos de régimen interno disciplinario, de trabajo.

- Todos los demás acuerdos que así establezca la Ley.

Como añadido posee además la facultad de debatir sobre cuantos asuntos sean de interés para la cooperativa (artículo 31, 4 LCV). Pero 
únicamente podrá tomar acuerdos obligatorios en materias que esta Ley no considere competencia exclusiva de otro órgano social.

\section{b) Convocatoria de la Asamblea}

La Asamblea tiene muchas competencias, pero se pueden resumir en dos contenidos fundamentales:

- Aprobación de cuentas y gestión de los administradores.

- Cualquier modificación de los Estatutos.

Una sociedad no tiene que estar modificando los Estatutos ante cualquier motivo. A diferencia que otras sociedades, cuando la cooperativa quiere aumentar el activo patrimonial mediante ampliación del capital social, no hace falta modificación estatutaria, ya que son sociedades de capital variable mediante la aplicación del excedente. Por eso la Asamblea tiene que reunirse como mínimo necesario para aprobar las cuentas y consecuentemente para aprobar la gestión de éstas. Así pues, el artículo 32 LCV establece dos tipos de reunión:

\section{- Asamblea ordinaria:}

Es la mínima anual en cada ejercicio en los 6 primeros meses tras el cierre del ejercicio anterior. Corresponde al Consejo Rector su convocatoria.

Si por cualquier causa transcurre el plazo citado de los 6 meses sin que la convocatoria se haya efectuado, cualquier socio podrá requerir al consejo rector que la convoque. Si no lo hace en el plazo de 15 días el socio podrá solicitar la convocatoria del juez de distrito del domicilio social, quien lo ordenara, designando a la persona que habrá de presidir la Asamblea.

\section{- Asamblea extraordinaria:}

Son, en definitiva, aquellas reuniones que no son ordinarias. Se trata de las reuniones de la Asamblea que no tengan como fin fundamental el examen de las cuentas anuales.

Pueden ser convocadas por los administradores, por el Consejo de Vigilancia, en el caso de que éste exista, y por los socios que representen al menos el $20 \%$ del voto social. En su defecto, podrán acudir al juez y convocar junta extraordinaria judicialmente. 
Puede suceder que una junta se convoque espontáneamente. Será válida la reunión, únicamente si, estando presentes o representados todos los socios, deciden unánimemente la celebración de la Asamblea, salvo que alguien no esté de acuerdo y quiera seguir la formalidad legal.

\section{c) FunCiOnAMiento}

En el artículo 34, 1 LVC se especifica que «la Asamblea General, salvo que tenga el carácter de universal, se celebrará en la localidad donde esté el domicilio social. Los Estatutos, en los casos en que exista causa que lo justifique podrán fijar con carácter general otros lugares de reunión o los criterios a seguir por los administradores para la determinación del lugar de celebración de la misma». En resumen, debe celebrarse, como norma general, en la localidad donde radica el domicilio social salvo si el Estatuto fija otros lugares de reunión con causa justificada.

Seguidamente, el artículo 34, 2 LVC afirma que la Asamblea queda válidamente constituida en primera convocatoria cuando estén presentes o representados la mayoría de los votos, y en segunda convocatoria cuando estén al menos los socios que ostenten el $10 \%$ de los votos o en su defecto 100 votos.

\section{d) DERECHO dE VOto Y REPRESENTACIÓN}

La cooperativa es una sociedad de personas en la que el capital tiene un carácter instrumental, razón por la que los votos no vayan en proporción a las aportación de capital.

Conforme al principio de participación universal, TODOS los socios, con independencia de su categoría personal y su aportación de capital, tienen el mismo voto, es decir, que atiende a regla del artículo 35, 1 LVC de «un socio, un voto». Pero la Ley permite, vía estatuaria, graduar el voto en aquellas cooperativas en donde hay varias cooperativas integradas por personas jurídicas. Así lo expone la LVC en artículo 35, 2, en el que se afirma que el voto puede ser graduado para los socios que «sean cooperativas, sociedades controladas por éstas o a las Entidades Públicas sea proporcional a la actividad cooperativa de la sociedad».

A su vez, el artículo 34, 4 LVC admite la existencia del derecho de representación. Se puede practicar siempre que los Estatutos no exi- 
jan una presencia personal, en cuyo caso, se impone la participación no representada.

Esta representación se caracteriza por los siguientes rasgos:

— debe ser entre socios

- está limitada en cuanto a la cuantía del voto, porque ningún socio podrá tener más representaciones que la suya y la de otros dos

- para su autorización, es necesario que se haga por escrito con carácter especial para cada Asamblea a la que asista como representante.

\section{e) AdOPCIÓN DE ACUERDOS}

A tenor del artículo 36, 1 LVC, como norma general, los acuerdos de la Asamblea General se adoptan por mayoría simple, que se entenderá por ésta, la constituida por más de la mitad de los votos. Pero, añade a su vez, que la mayoría debe computarse teniendo en cuenta los votos presentes y representados, válidamente emitidos, descontando con ello las abstenciones y los votos nulos y en blanco.

Asimismo, añade el artículo 36, 2 LVC, que existen algunos supuestos, que exigen mayoría de dos tercios de los votos presentes o representados cuando en el orden del día las modificaciones estatutarias se refieran a los siguientes casos:

- transformación del tipo social

- fusión de la sociedad

- escisión de la compañía

— disolución de la sociedad.

Como en las votaciones puede darse el empate, los Estatutos pueden prever que el voto del presidente de la Asamblea sea de calidad y dirima la cuestión a favor de la postura que él hubiese adoptado.

Finalmente, y como anota el artículo 37, 1 LVC «los acuerdos de la Asamblea General se consignarán en acta, que redactará el Secretario y transcribirá en el libro de actas». El acta, una vez redactada por el Secretario, puede ser aprobada por la propia Asamblea a continuación de haberse celebrado ésta o, como otra alternativa, en los próximos quince días contados a partir de la celebración de la misma, y que será firmada por el Presidente, el Secretario y dos socios designados por la Asamblea (artículo 37, 3 LVC) 


\section{f) IMPUGNACIÓN DE ACUERDOS}

Los acuerdos de la Asamblea pueden ser impugnados, tanto por nulidad, como por anulabilidad. El resultado final es el mismo: el acuerdo deviene ilegítimo.

Hay, por tanto, dos formas de impugnación:

- Nulidad:

Pueden impugnarse por nulidad los acuerdos que vulneren cualquier ley, no un reglamento (artículo 39, 2 LVC). Todo socio, los administradores, los miembros de la Comisión de Vigilancia y cualquier tercero afectado con interés legítimo puede ejercer la acción de impugnación, cuyo plazo de caducidad es de un año (artículo 39, 4 LVC).

-Anulabilidad:

Son impugnables por anulabilidad aquellos actos que vulneren los Estatutos o lesionen en beneficio de uno o varios socios o de terceros los intereses de la compañía (artículo 392 LVC). Pueden ejercitar esta acción, los socios asistentes a la asamblea que hayan hecho constar en acta su oposición al acuerdo, los que hayan sido privados ilegítimamente del derecho de voto, los administradores y los miembros de la Comisión de Vigilancia. La caducidad de las acciones para este tipo de impugnación es de cuarenta días (artículo 39, 5 LVC).

El procedimiento para interponer la impugnación viene recogido en el artículo 39, 7 LVC, que remite ello a los artículos 118 a 121 de la Ley de Régimen Jurídico de las Sociedades Anónimas (en adelante LSA). Dado que los artículos 119 a 121 LSA han sido derogados por la Disposición Derogatoria Única de la Ley 1/2000, de 7 de enero, de Enjuiciamiento Civil, el artículo 118 LSA indica que "para la impugnación de los acuerdos sociales se seguirán los tramites del juicio ordinario y las disposiciones contenidas en la Ley de Enjuiciamiento Civil».

En todo caso, la sentencia estimatoria de la acción de impugnación, producirá efectos ante todos los socios, pero no afectará a los derechos adquiridos por terceros de buena fe (artículo 39, 8 LVC). Lo que sucederá es que habrá que asumir responsabilidad por los administradores o por aquellos que hayan llevado a cabo el acuerdo. 


\subsection{Consejo Rector}

El Consejo Rector es el órgano de gobierno, gestión y representación de la cooperativas, constituyéndose en un órgano delegado de la Asamblea General, ya que ésta puede conocer de todos los asuntos relativos a la cooperativa.

La razón de la existencia de este órgano estriba en que la Asamblea General no puede reunirse continuamente para adoptar las decisiones precisas ante determinadas situaciones, siendo necesario un órgano gestor de mayor agilidad, como es el Consejo Rector, que a su vez podrá delegar facultades en otros órganos.

Así, dice bien el artículo 40, 1 LVC, que «los administradores son el órgano al que corresponde en exclusiva la gestión y representación de la cooperativa y ejercen además todas las facultades que no estén expresamente reservadas por la Ley o los Estatutos a otros órganos sociales».

\section{a) COMPETEnCIAS}

El Consejo Rector tiene, por tanto, una competencia residual que además no es excluyente. Sin embargo, la Ley señala algunas facultades y funciones específicas de este órgano social, como son las señaladas en el artículo 40, 2 LVC («los Estatutos deberán determinar el modo en que se ejerza la representación atribuida a los administradores, que se extenderá, en juicio o fuera de él, a todos los actos comprendidos en el objeto social. Cualquier limitación estatutaria de las facultades representativas de los administrativas será ineficaz frente a terceros. La cooperativa quedará obligada frente a terceros que hayan obrado de buena fe y sin culpa grave, aunque se desprenda de los Estatutos que el acto no está comprendido en el objeto social»). Así, entre sus facultades, se distinguen dos tipos de actos:

-Típicos:

Son aquellos comprendidos en el objeto y obligan a la cooperativa a todos los actos comprendidos en éste. Cualquier limitación incluso estatutaria será, por lo tanto, ineficaz ante terceros.

-Atípicos:

Son aquellos actos en los que la sociedad quedará obligada frente a terceros de buena fe y sin culpa grave. 
Sus facultades abarcan todas las concernientes al gobierno, gestión y representación de la cooperativa, salvo aquellas que estuvieran expresamente reservadas por la Ley o los Estatutos a la Asamblea General u otros órganos sociales.

El Consejo Rector tiene, por tanto, una competencia residual que además no es excluyente. Sin embargo, y dentro de este marco, la Ley señala algunas facultades $\boldsymbol{y}$ funciones específicas de este órgano social, entre las que pueden señalarse las siguientes:

— La admisión de los socios. El artículo 20, 3 LVC señala que»la solicitud de admisión se formulará por escrito a los administradores que resolverán en un plazo no superior a sesenta días a contar desde la recepción de aquéllas, debiendo ser motivada la decisión desfavorable a la admisión».

- Cumplimiento del derecho de información. Según el artículo 24, 2b LVC se afirma que todo socio tiene derecho, con respecto al derecho de información, de examinar el libro registro de socios de la cooperativa y el libro de actas de la Asamblea General, y, en caso de que lo solicite, "los administradores deberán proporcionarle copia certificada del acta y de los acuerdos adoptados en la Asamblea General, y certificación de las inscripciones en el libro registro de socios previa solicitud motivada». Seguidamente, se señala en el artículo 24, 2d LVC, que el socio y los órganos que a éstos representen (artículo 24, 6 LVC), tienen derecho a que se les informe por parte de los administradores, al menos trimestralmente "sobre su situación socio-económica en relación con la cooperativa».

- Expulsión de socios. Esta sólo podrá ser acordada por los administradores, por falta muy grave tipificada en los Estatutos, mediante expediente instruido al efecto y con audiencia del socio interesado (artículo 28, 1 LCV).

-Admisión en algunos supuestos de aportaciones voluntarias al capital social. Así, el artículo 59, 2 LVC admite que los administradores podrán aceptar en todo momento este tipo de aportaciones, no pudiendo ser la retribución superior a la de las últimas aportaciones voluntarias al capital acordadas por la Asamblea o a la de las aportaciones obligatorias.

Por mandato de la Ley, los Estatutos deben establecer, además de la composición y funcionamiento del Consejo Rector, su competencia. En cumplimiento de esta obligación conviene no sólo establecer su 
marco de actuación de una forma genérica, sino detallar algunas facultades especificas así como las relaciones con terceros, la realización de escrituras y, en general el ejercicio de la representación de la cooperativa. Así, a modo de ejemplo, pueden señalarse esquemáticamente las siguientes facultades:

- Contratar al personal necesario

- Efectuar los actos y celebrar los contratos necesarios o convenientes para la realización del objeto social.

- Adquirir, gravar y enajenar bienes muebles e inmuebles.

- Acordar lo conveniente sobre el ejercicio de acciones ante toda clase de juzgados y tribunales.

- Conferir poderes a personas determinadas.

- Representar a la cooperativa ante toda clase de autoridades, corporaciones u organismos, etc

b) Funcionamiento

Los administradores, que se configuran como un órgano colegiado (excepto en cooperativas con un numero de socios no superior a diez) serán designados por la Asamblea General en voto secreto y por un plazo mínimo y máximo de dos y cinco años respectivamente (artículo 41, 3 LVC). El cargo de administrador no es remunerado a no ser que se establezca por vía estatutaria o en base a un acuerdo asambleario a la hora de su designación (artículo 43 LVC).

El Consejo será citado en única convocatoria, estableciéndose el orden del día y acompañándose la documentación oportuna para el debate y la votación. Para que el Consejo Rector quede válidamente constituido y pueda adoptar acuerdos, es preciso un quórum de asistencia de la mitad mas uno de los componentes (artículo 46 LVC).

\section{c) AdOPCIÓN DE ACUERDOS}

A tenor del artículo 46, 3 LVC, como norma general «los acuerdos se adoptarán por más de la mitad de los votos de los asistentes», salvo que se disponga otra cosa legal o estatutariamente.

Asimismo, en el mismo artículo, párrafo segundo, se establecen cuatro casos en los que se exige la adopción de acuerdos en el Consejo a través de una mayoría reforzada de dos tercios de los asistentes, siendo éstos los siguientes: 
- acuerdo que implique cierre o traslado de factorías

- acuerdo por los que va a proponer a la Asamblea alteraciones sustanciales de la organización de la sociedad

- cambios en la propia organización productiva

- aquellas funciones que aparecen en artículo 33, 1 LVC (competencias de la Asamblea General, pero delegables al Consejo).

Los acuerdos del Consejo, en base al artículo 46, 4 LVC «serán llevados a un libro de actas que será firmado por el Presidente y el Secretario y recogerán los debates en forma sucinta y el texto de los acuerdos, así como los resultados de las votaciones».

\section{d) ReSPONSABILIDAD}

Todos los administradores del Consejo tienen una responsabilidad por los actos de administración, de carácter profesional. Así, el número 47, 2 LVC articula que todos los miembros que adoptaron el acuerdo lesivo, responderán de manera solidaria, a excepción de «aquellos que prueben que, no habiendo intervenido en su adopción o ejecución, desconocían su existencia, o, en caso de conocerla, hicieron todo lo posible para evitar el daño, o al menos se opusieron expresamente». se responde, por tanto, solidaria e ilimitadamente de las resultas del daño social, frente al interés de la sociedad, del socio o de terceros.

\section{e) IMPUGNACIÓN DE ACUERDOS}

El artículo 49 LVC regula la posibilidad de impugnación de acuerdos lesivos, por lo que pueden ser impugnados los acuerdos del Consejo que sean contrarios a la Ley o a los Estatutos, que lesionen los intereses de la sociedad en beneficio de uno o varios socios o de terceros.

Al igual que ocurría con la impugnación de los acuerdos de la Asamblea General, en este caso, la impugnación puede ser igualmente por nulidad y por anulabilidad:

—Nulidad:

Se impugnarán por nulidad los acuerdos que lesionan la Ley (no reglamentos), por parte de cualquier administrador, por la Comisión de Vigilancia y por cualquier socio en general. 


\section{- Anulabilidad:}

Se trata de aquellos acuerdos que vulneren los Estatutos sociales. Los podrán impugnar, al igual que en el caso de impugnación por nulidad, los administradores y la Comisión de Vigilancia, y asimismo, los socios que representen el $10 \%$ de los votos sociales.

En todo caso, el plazo para practicar la acción de impugnación es de sesenta días y se tramitará con arreglo a lo establecido para la impugnación de acuerdos de la Asamblea, es decir, en base al artículo 118 LSA.

\section{D) LEY DE COOPERATIVAS}

\section{Consideraciones previas}

El mandato de la Constitución Española que ordena a los poderes públicos el fomento mediante una legislación adecuada de las sociedades cooperativas en el artículo 129, 2 CE motiva a que se contemple la necesidad de ofrecer un cauce adecuado que canalice las iniciativas colectivas de los ciudadanos que desarrollen actividades generadoras de riqueza estable.

La legislación nacional a la que nos vamos a referir, la nueva Ley 27/ 1999 de Cooperativas de 16 de Julio, tiene en cuenta, al igual que la legislación de cooperativas anterior, la adaptación de las exigencias del Estado de las Autonomías, el régimen jurídico de las sociedades cooperativas. El asumir las Comunidades Autónomas la competencia exclusiva en esta materia significa, en la práctica, que el ámbito de aplicación de la nueva Ley ha sido ampliamente reformulado, por lo que hace necesaria una definición del mismo. Así, el artículo 2 Ley de Cooperativas (en adelante LC) delimita su ámbito de aplicación a «las sociedades cooperativas que desarrollen su actividad cooperativizada en el territorio de varias Comunidades Autónomas, excepto cuando en una de ellas se desarrolle con carácter principal».

El alcance, por tanto, del ámbito de aplicación de la nueva Ley es estatal, al que se acogerán las sociedades cooperativas que desarrollen su actividad en este ámbito. 
La Ley ofrece un marco de flexibilidad, donde las propias cooperativas puedan entrar a autorregularse, y establece los principios que, con carácter general, deben ser aplicados en su actuación.

A continuación nos centraremos, al igual que en el caso anterior, en la regulación de los órganos de control y de gobierno de la sociedad cooperativa de la LC.

\section{Organos Sociales de la Sociedad Cooperativa}

Primeramente hay que señalar que es el artículo 19 LC el que expone tales órganos de la compañía, señalando a la Asamblea General, el Consejo Rector y la Intervención como órganos sociales de la sociedad cooperativa. A diferencia que la anteriormente estudiada Ley Vasca de Cooperativas, la LC introduce la Intervención como órgano de la sociedad en materia de fiscalización de la cooperativa.

\subsection{Asamblea General}

El concepto de la Asamblea General está recogido en el primer artículo de la sección segunda del capítulo cuarto del título primero de LC. Se trata pues de la reunión de todos los socios. Se constituye con el objeto de deliberar y adoptar acuerdos sobre los asuntos para los que es competente, bien sean de carácter legal o estatutario. Las decisiones, al igual que en la LVC, son obligadas para TODOS los socios de la cooperativa.

\section{a) COMPETEnCIAS}

Este órgano está dotado de un número determinado de facultades ejercidas con carácter de exclusividad, por lo que sólo puede establecer acuerdos obligados a todos en el ámbito de las materias que la LC no establezca sean competencia de otro órgano de la sociedad. Pero esto no es obstáculo para que la Asamblea pueda ofrecer instrucciones al Consejo Rector o también, como expresa el artículo 21, 1 LC «someter a autorización la adopción por dicho órgano de decisiones o acuerdos sobre determinados asuntos», si los Estatutos no establecen otra cosa.

Al igual que ocurre en la LVC, la Asamblea está dotada de unas competencias exclusivas, indelegables, bien provengan de la Ley o de 
los Estatutos sociales. Éstas, que son equivalentes a las competencias que para este órgano se recogen en la LVC, se encuentran recogidas en el artículo 21, 2 LC y son las siguientes:

— «Examen de la gestión social, aprobación de las cuentas anuales, del informe de gestión y de la aplicación de los excedentes disponibles o imputación de las pérdidas.

- Nombramiento y revocación de los miembros del Consejo Rector, de los interventores, de los auditores de cuentas, de los liquidadores $y$, en su caso, el nombramiento del Comité de Recursos, así como sobre la cuantía de la retribución de los consejeros y de los liquidadores. No se especifica aquí, como en la LVC, el carácter secreto de la votación, pero el artículo 25, 3 LC establece que "las votaciones serán secretas en los supuestos previstos en la presente Ley o en los Estatutos, además de en aquellos en que así lo aprueben, previa su votación a solicitud de cualquier socio, el $10 \%$ de los votos sociales presentes y representados en la Asamblea General».

- Modificación de los Estatutos y aprobación o modificación, en su caso, del Reglamento de régimen interno de la cooperativa, se refiere a la aprobación de reglamentos de régimen interno disciplinario, de trabajo.

- Aprobación de nuevas aportaciones obligatorias, admisión de aportaciones al capital social, fijación de las aportaciones de los nuevos socios, establecimiento de cuotas de ingreso o periódicas, así como el tipo de interés a abonar por las aportaciones al capital social.

—Emisión de obligaciones, títulos participativos, participaciones especiales $u$ otras formas de financiación mediante emisiones de valores negociables.

-Fusión, escisión, transformación y disolución de la sociedad.

- Toda decisión que suponga una modificación sustancial, según los Estatutos, de la estructura económica, social, organizativa o funcional de la cooperativa, cualquiera que sea su naturaleza.

- Constitución de cooperativas de segundo grado y de grupos cooperativos o incorporación a éstos si ya están constituidos, participación en otras formas de colaboración económica contemplada en el artículo 79 de esta Ley, adhesión a entidades de carácter representativo así como la separación de las mismas. El artículo 79 de la LC se refiere a otras formas de colaboración económica. Se recogen tres tipos de la misma: 
- Las cooperativas de cualquier tipo y clase podrán constituir sociedades, agrupaciones, consorcios y uniones entre sí, o con otras personas físicas o jurídicas, públicas o privadas, y formalizar acuerdos o convenios.

- Las cooperativas que concentren sus empresas por fusión o por constitución de otras cooperativas de segundo grado, así como mediante uniones temporales.

- Las cooperativas podrán suscribir con otras acuerdos intercooperativos.

- El ejercicio de la acción social de responsabilidad contra los miembros del Consejo Rector, los auditores de cuentas y liquidadores.

- Los derivados de una norma legal o estatutaria».

El apartado tercero de este mismo artículo añade que estas competencias son indelegables, "salvo aquellas que puedan ser delegadas en el grupo cooperativo regulado en el artículo 78 de esta Ley». Por grupo cooperativo entiende el artículo citado, que es el «conjunto formado por varias sociedades cooperativas, cualquiera que sea su clase, y la entidad cabeza de grupo que ejercita facultades o emite instrucciones de obligado cumplimiento para las cooperativas, de forma que se produce una unidad de decisión en el ámbito de dichas facultades».

\section{b) Convocatoria de la Asamblea}

Al igual que en la regulación vasca, en la LC las convocatorias de la Asamblea son iguales. También se puede diferenciar aquí entre una Asamblea de carácter ordinario y otra de carácter extraordinario. Se pasará, por tanto, a examinar a continuación, los artículos que de ello tratan, los artículos 22 y 23 LC:

-Asamblea ordinaria:

Examina la gestión social y aprueba las cuentas anuales, en su caso, pudiendo asimismo tratar de cualquier otro asunto que sea propio de las competencias de este órgano.

Al igual que en la convocatoria ordinaria recogida en la LVC, deberá reunirse en los seis meses siguientes a la fecha de cierre del ejercicio, siendo el Consejo Rector el que deba proceder a su convocatoria. 
A diferencia que ocurre en la LVC, en la que se admite que cualquier socio está legitimado para poder pedir la convocatoria de la Asamblea ordinaria tras haber transcurrido el plazo legal para ello (seis meses tras el cierre del ejercicio), la LC también lo permite, pero no está legitimado para ello cualquier socio, sino que son los Interventores los que tiene esta facultad, que deberán reclamarla al Consejo Rector. Si en el plazo de quince días tampoco se convoca, deberá solicitarla al juez competente, es decir, al Juez de Primera Instancia del domicilio en que se encuentre la compañía. Es entonces aquí, cuando están legitimados ya todos los socios para recurrir al juez.

- Asamblea extraordinaria:

Por exclusión, son todas aquellas reuniones que no son ordinarias.

Mientras en la LVC este tipo de Asamblea puede ser convocada también por el Consejo de Vigilancia en el caso de que éste exista, no recoge la iniciativa de este órgano la LC. A tenor de esta última Ley, será convocada la Asamblea extraordinaria por el Consejo Rector a petición de los socios que representen el $20 \%$ de los votos y en el caso de que así lo prevean los Estatutos, también a solicitud de los Interventores. Si el Consejo no atiende a sus pretensiones, podrán recurrir al juez competente.

Puede suceder que una junta se convoque espontáneamente. Será válida la reunión, únicamente si, estando presentes o representados todos los socios, deciden unánimemente la celebración de la Asamblea, salvo que alguien no esté de acuerdo y quiera seguir la formalidad legal. Así lo permite el artículo 23, 5 LC.

\section{c) Funcionamiento}

Inicialmente es necesario decir, que si bien la LVC establece el lugar del domicilio social como lugar determinado para la organización de las reuniones de la Asamblea. Sin embargo, la LC no consta esta determinación, por lo que su determinación sería de libre disposición.

La Asamblea queda válidamente constituida según los términos del artículo 25 LC. Así, en primera convocatoria será válida la reunión cuando estén presentes o representados más de la mitad de los votos 
sociales. En segunda convocatoria será válida aquella en la que estén presentes o representados al menos el $10 \%$ de los votos o 100 votos, lo que se corresponde asimismo a lo que regula la LVC.

\section{d) DeRECHO DE VOto Y REPRESENTACIÓN}

Uno de los rasgos básicos de la sociedad cooperativa es que a cada socio le corresponde un voto.

Con respecto al régimen del derecho de voto que establece la LC, concuerda con lo que establece la LVC, que, a su vez, en el artículo 26, 2 LC admite el voto plural ponderado que corresponde con el voto proporcional que establece la LVC. Así, los Estatutos pueden establecer este tipo de voto para las cooperativas de primer grado para los socios que sean cooperativas, sociedades controladas por éstas o entidades públicas.

Asimismo, admite la LC el derecho de representación en su artículo 27. Se puede practicar siempre que el socio no acumule más de dos representaciones y siempre que no se lo impida algún tipo de normativa. Si bien la LVC ya especifica en su artículo 34 cómo debe hacerse la delegación del derecho de voto, la LC remite para este asunto al Estatuto propio de cada sociedad (artículo 27, 3 LC).

\section{e) ADOPCIÓN DE ACUERDOS}

Como norma general, la LC establece la misma mayoría para los acuerdos que la que establece la LVC, es decir, la mayoría simple (artículo 28, 1 LC), descontando los votos en blanco y las abstenciones.

Pero, asimismo, el siguiente párrafo del mismo artículo establece una mayoría cualificada de dos tercios de los votos presentes y representados para aquellos acuerdos en los que haya que adoptar los siguientes acuerdos:

- modificación de Estatutos

— adhesión o baja en un grupo cooperativo

— transformación, fusión, escisión, disolución y reactivación de la sociedad.

Para estos casos, los Estatutos también podrán establecer mayorías superiores. La LC no regula nada acerca de la adopción de acuerdos en los que se da el empate. 
Los acuerdos de la Asamblea, tal y como anota el artículo 28,5 LC producirán efectos desde su adopción y se consignarán en acta, que será redactada por el Secretario, al igual que ocurre en la LVC. Asimismo, podrá ser aprobada el acta a continuación de la celebración del acuerdo o, dentro del plazo de quince días, por el Presidente de la Asamblea y dos socios designados por la misma, que la firmarán con el Secretario (artículo 29, 2 LC).

\section{f) IMPUGNACIÓN DE ACUERDOS}

Los acuerdos de la Asamblea pueden ser impugnados a tenor de lo que así establece el artículo 31 LC. Para el procedimiento de impugnación, se remite a la Ley de Sociedades Anónimas en sus artículos 118 a 121 en los que se establece que «se seguirán los tramites del juicio ordinario y las disposiciones contenidas en la Ley de Enjuiciamiento Civil».

Los efectos que produce la sentencia proveniente de la impugnación son frente a todos los socios, no así a los derechos adquiridos por terceros de buena fe.

Existen dos tipos de impugnación:

- Nulidad:

La impugnación por nulidad se lleva a cabo en los casos en que los acuerdos sean contrarios a la Ley. Esta acción tiene un plazo de caducidad, que corresponde a un año, salvo para los casos específicos en que éstos resulten contrarios al orden público. La legitimación activa para este tipo de impugnación corresponde a cualquier socio, los administradores, los interventores, el Comité de Recursos y los terceros que tengan un interés legítimo.

- Anulabilidad:

Son anulables todos aquellos acuerdos que no puedan impugnarse por nulidad. El plazo de caducidad difiere de la nulidad, otorgando aquí un plazo de cuarenta días para proceder a su anulación. Pueden ejercitar esta acción, los socios asistentes a la asamblea que hayan hecho constar en acta su oposición al acuerdo, los que hayan sido privados ilegítimamente del derecho de voto, los administradores y el Comité de Recursos, así como los interventores. 
A diferencia de la LVC, amplía aquí la legitimación para impugnar acuerdos al Comité de Recursos y a los miembros de la Intervención.

\subsection{El Consejo Rector}

Se trata del órgano de gobierno, al que corresponde, como mínimo, la gestión, la supervisión de los directivos y la representación de la compañía de todos los actos relacionados con las actividades que integren el objeto social de la compañía. Es un órgano de mayor soltura, que se ocupa de todo aquello de lo que no puede encargarse la Asamblea General.

\section{a) COMPETENCIAS}

Si bien el Consejo tiene tal competencia residual, sin embargo, el artículo 32, 1 LC señala que «corresponde al Consejo Rector cuantas facultades no estén reservadas por Ley o por Estatutos a otros órganos». así, la Ley señala algunas de las facultades atribuidas a este órgano, previstas en el artículo 32 LC:

- "Acordar, en su caso, la modificación de los Estatutos cuando consista en el cambio del domicilio social dentro del mismo término municipal.

- Conferir apoderamientos, así como proceder a su revocación, a cualquier persona y a nombrar y revocar al gerente, director general o cargo equivalente, como apoderado principal de la cooperativa».

A distinción de lo regulado en la LVC no se especifica aquí ninguna competencia del Consejo Rector sobre el derecho de información. El abanico de competencias en la LC es mucho más reducido.

\section{b) FunCIONAMIENTO}

La composición de este órgano viene determinada en el artículo 33 LC. Se afirma que será establecida por los Estatutos, pero, en todo caso, debe de estar entre el límite de tres y quince consejeros. Los cargos son elegidos por mayoría y votación secreta por la Asamblea General por un período establecido estatutariamente (de entre tres y seis años) y posible reelección (artículo 35, 1 LC). Tal nombramiento se hará efectivo desde el momento de su aceptación (artículo 34 LC). 
El Consejo Rector, como órgano colegiado, a la hora de su renovación, se procederá a ella en la totalidad de sus miembros, a no ser que vía estatutaria se haya establecido un régimen distinto para este caso.

\section{c) ADOPCIÓN DE ACUERDOS}

Cada socio del Consejo está revestido de un voto y los acuerdos serán entendidos válidos, en tanto se consiga una mayoría de los votos válidamente emitidos. Como requisito previo, es necesario que concurra la reunión de más de la mitad de los miembros para que la convocatoria pueda desenvolverse eficazmente (artículo 36 LC).

A disconformidad con la LVC no se señala en esta Ley ningún caso específico para el que se requiera una mayoría reforzada, pero sí establece, por otra parte, que será el Presidente quien dirima la cuestión en caso de que se establezca un empate (artículo 36, 4 LC).

Los acuerdos adoptados se recogerán también en acta, firmada por el Secretario y el Presidente (artículo 36, 5 LC).

\section{d) ResponsabiLIDAD}

La responsabilidad de los miembros del Consejo viene regulada conjuntamente con la de los miembros de la Intervención en la sección quinta, artículo 43 LC. Este artículo remite a la Ley de Sociedades Anónimas, que en su artículo 133 afirma que serán responsables del daño que causen por los actos contrarios a la Ley, a los Estatutos sociales y a los realizados sin la diligencia con la que deben desempeñar sus funciones.

\section{e) IMPUGNACIÓN DE ACUERDOS}

El artículo 37 LC regula la posibilidad de impugnar los acuerdos adoptados por el Consejo. Al igual que ocurría con la Asamblea General, caben las impugnaciones de dos tipos:

—Nulidad:

Se impugnarán por nulidad los acuerdos que lesionan la Ley por los socios incluyendo a los miembros del Consejo Rector, que hubieran votado a favor del acuerdo adoptado. Para ello tendrán el plazo de dos meses. 
- Anulabilidad:

Es aquella acción utilizada para el caso de que se lesionen los Estatutos sociales. En ese caso están legitimados para impugnar en el plazo de un mes los asistentes a la reunión del Consejo, que hayan hecho constar en acta su contraposición del acuerdo adoptado, los ausentes y los que hayan sido privados de su derecho de voto de forma ilegítima y, asimismo, los interventores y el $5 \%$ de sus socios.

\subsection{La Intervención}

La LC regula, aparte, en la sección cuarta, el órgano de la Intervención. Se trata éste del órgano de fiscalización de la sociedad, en el que no sólo se delegan facultades vía legal, sino también vía estatutaria. Así pues, se han ido viendo a lo largo del estudio de los órganos de la cooperativa regulados en la LC diversas facultades de los miembros de este órgano, que se recogen en las siguientes:

- Respecto de la Asamblea General:

- Convocatoria:

A tenor del artículo 23 LC la Asamblea General ordinaria deberá reunirse en los seis primeros meses a la fecha del ejercicio económico por el Consejo Rector. En el caso de que este último no la convoque, es labor de los Interventores reclamar su reunión al Consejo Rector y, en caso de incumplimiento, tras quince días deberán éstos recurrir a la autoridad judicial.

En cuanto a la Asamblea General extraordinaria, también es labor de los Interventores (entre otros legitimados) reclamar su convocatoria al Consejo Rector.

- Impugnación de acuerdos:

La impugnación de los acuerdos procede cuando éstos vulneran bien la Ley (nulidad) o bien los Estatutos sociales o los intereses de la cooperativa (anulabilidad). A tenor del artículo 31, 4 y 5 LC los Interventores tienen potestad para impugnar un acuerdo en ambas modalidades.

- Respecto del Consejo Rector:

El artículo 37 LC afirma que la impugnación de acuerdos anulables puede darse, entre otros, por los Interventores. 
- Consulta y comprobación:

El artículo 38, 1 LC regula la consulta y la comprobación por parte de este órgano de toda aquella documentación de la sociedad que estime oportuna y, asimismo, de proceder a sus verificaciones.

Los Interventores están sometidos a responsabilidad, que como ya se ha dicho anteriormente, se regula en el artículo 43 LC junto con la de los consejeros. Así, son responsables pues, del daño que causen por los actos contrarios a la Ley, a los Estatutos sociales y a los realizados sin la diligencia con la que deben desempeñar su cargo. Si bien para los consejeros puede darse, no se establece para los Interventores la responsabilidad solidaria.

\section{E) ESTATUTO DE LA SOCIEDAD COOPERATIVA EUROPEA}

\section{Consideraciones previas}

La realización del mercado interior y la mejora de la situación económica y social implican, además de la eliminación de los obstáculos a los intercambios, una reestructuración a escala de la comunidad de las estructuras de producción. A tal fin, es indispensable, que las empresas de todo tipo, cuya actividad no se limite a satisfacer necesidades puramente locales puedan concebir y llevar a cabo la reorganización de sus actividades a escala comunitaria.

Es necesario considerar el marco jurídico aplicable a la actividad económica dentro de la Comunidad, que seguirá basándose, en gran medida, en las legislaciones nacionales, lo que puede entorpecer considerablemente la situación las operaciones de agrupamiento entre sociedades sometidas a las legislaciones de los distintos Estados miembros.

Por otra parte, la Agrupación Europea de Interés económico (AEIE), aunque permite fomentar determinadas actividades de manera conjunta, no satisface las necesidades específicas de las cooperativas. Por ello, la Comunidad, en su afán por respetar la igualdad de condiciones de la competencia y contribuir a su desarrollo económico, debe dotar a las cooperativas de instrumentos jurídicos adecuados para que permitan facilitar el desarrollo de sus actividades transfronterizas. Las Naciones Unidas han instado a todos los Estados a asegurar un entor- 
no propicio en el que las cooperativas puedan participar en igualdad de condiciones con otras formas de empresa.

Ante todo, las cooperativas son agrupaciones de personas o entidades jurídicas que se rigen por principios de funcionamiento específicos, distintos de los otros agentes económicos. Entre esos principios cabe mencionar el de estructura y gestión democráticas y el de distribución equitativa del beneficio neto del ejercicio financiero. En definitiva, estos principios se refieren especialmente al principio de primacía de la persona, que se refleja en disposiciones específicas relativas a las condiciones de adhesión, renuncia y exclusión de los socios; dicho principio se traduce en la regla «un socio, un voto», que vincula el derecho de voto a la persona e implica la imposibilidad de que los miembros ejerzan un derecho sobre el activo de la sociedad cooperativa.

El objetivo principal de la Sociedad Cooperativa Europea (en adelante SCE) debe ser la satisfacción de las necesidades de sus socios y el desarrollo de sus actividades económicas y sociales, debiendo para ello estar dotada de los órganos sociales que permitan llevar esto a cabo.

\section{Organos Sociales de la Sociedad Cooperativa Europea}

Conforme a las condiciones establecidas en el artículo 36 del reglamento, la SCE constará de:

a) Asamblea General.

b) Organo de Control y Organo de Dirección, si se basa en un sistema dual, o un Organo de Administración si se constituye en base de un sistema monista. La opción elegida será según se haya adoptado en los estatutos.

\subsection{Asamblea General}

El órgano de la Asamblea General está recogido en la sección cuarta del Reglamento de SCE, pero no hay ninguna definición explícita de la misma. La definimos pues, como anteriormente se ha venido tratando, como la reunión de todos los socios. Se constituye con el objeto de deliberar y adoptar acuerdos sobre los asuntos para los que es competente, bien sean de carácter legal o estatutario. Las decisiones, al igual que en la LVC, son obligadas para TODOS los socios de la cooperativa. 


\section{a) COMPETENCIAS}

La Asamblea General decidirá en aquellos asuntos respecto a los cuales se le confieren competencias específicas en base a:

-el reglamento

- las disposiciones de la legislación del estado miembro en que tenga su domicilio la SCE, adoptadas en aplicación de la directiva 2002/.../CE.

La Asamblea General decidirá asimismo en aquellos asuntos respecto de los cuales se confiera competencia a la Asamblea General de una cooperativa a la que se le aplique el Derecho del Estado miembro en que se encuentre el domicilio social de la SCE, ya sea por la legislación del Estado miembro, ya sea con arreglo a estatutos conformes a ésta (artículo 52 SCE).

En lo referente a la organización y en base al artículo 53 SCE, los procedimientos de votación y desarrollo de la Asamblea General, se regirán por la legislación aplicable a las cooperativas del Estado miembro del domicilio social de la SCE.

\section{b) Convocatoria de la Asamblea y funcionamiento}

La Asamblea General se reunirá al menos una vez cada año civil dentro de los seis meses siguientes al cierre del ejercicio, excepto en caso de que la legislación del Estado miembro del domicilio social de la SCE establezca una frecuencia mayor. No obstante, los Estados miembros podrán disponer que la primera Asamblea General pueda reunirse dentro de los 18 meses siguientes a la constitución de la sociedad.

La Asamblea General podrá ser convocada en todo momento por el Organo de Dirección o de Administración, el Organo de Control o cualquier otro órgano o autoridad competente, con arreglo a la legislación nacional aplicable a las cooperativas del Estado miembro del domicilio de la SCE. El Organo de Dirección deberá convocar una Asamblea General cuando así lo solicite el Organo de Control.

El orden del día incluirá, como mínimo, la aprobación de las cuentas anuales y la aplicación de los resultados. Dado que esto corresponde al mínimo legal, cabe señalar, que pueden incluirse nuevos puntos en el orden del día. Así, según el articulo 57 SCE, se establece que «podrá solicitar la inclusión de uno o más puntos adicionales en el or- 
den del día de una asamblea general cualquier grupo de socios de la SCE integrado por más de 5.000 socios o que posea al menos el $10 \%$ del total de los votos. Los estatutos podrán reducir estas magnitudes».

La Asamblea General podrá acordar, en el curso de una asamblea, que se convoque una nueva asamblea en la fecha y con el orden del día que ella misma establezca.

Además la convocatoria de la Asamblea General se realizará mediante el envío, ya sea por escrito a todas las personas facultadas para participar en la Asamblea General de la SCE, o bien mediante publicación en el Boletín Oficial Interno de la compañía.

\section{c) DERECHO DE VOTO Y REPRESENTACIÓN}

Al igual que el régimen del derecho de voto que establece la LVC y la LC, el Reglamento del Consejo por el que aprueba el Estatuto de la SCE, reconoce en sus consideraciones, la regla de «un hombre un voto».

De la misma manera ocurre con el derecho de participación y representación, debido a que se recoge los derechos que se establecen en la LVC y en la LC en los artículos 27 y 34 respectivamente. Así queda establecido en el artículo 58 del estatuto de la SCE que:

"1. Todos los socios tendrán voz y voto en la asamblea en relación con los puntos del orden del día.

2. Podrán asistir a la asamblea general sin derecho de voto los miembros de los órganos de la SCE, los tenedores de títulos distintos de las participaciones y de obligaciones tal como se definen en el artículo 64 y, si lo permiten los estatutos, cualquier otra persona habilitada para ello por la legislación del Estado del domicilio de la SCE.

3. Las personas con derecho de voto podrán hacerse representar en la asamblea general por un mandatario, con arreglo a las modalidades previstas en los estatutos.

Se fijará en los estatutos el número máximo de poderes que puede recibir un mandatario.

4. Los estatutos podrán autorizar el voto por correspondencia o el voto electrónico y fijarán sus modalidades.»

Para los casos de las SCE cuyos socios sean mayoritariamente cooperativas y se establece que el número de votos de un socio esté determinado por su participación en la actividad cooperativa, incluida su 
participación en el capital de la misma; el número de socios de cada entidad participante; o bien por ambos factores.

Para los inversores, la SCE se basará en la legislación aplicable a las cooperativas del Estado miembro en el que la SCE tenga su domicilio. No obstante, los derechos de voto del conjunto de los socios no inversores no podrán exceder del $25 \%$ del total de los derechos de voto.

\section{e) AdOPCIÓN DE ACUERDOS}

La Asamblea General podrá adoptar acuerdos sobre los puntos que figuren en su orden del día y sobre aquellos que hayan sido incluidos en el orden del día por una minoría de socios con arreglo al artículo 57 SCE, mencionado anteriormente.

La decisión de la Asamblea General se hará por mayoría de los votos válidos emitidos por los socios presentes o representados. Aunque los requisitos necesarios para el quórum y la mayoría aplicable se fijaran en los estatutos de cada sociedad.

\subsection{Sistema Dual: Organo de Dirección y de Control}

a) Competencias

Las funciones del Organo de Dirección y la designación de sus miembros se señalan en los artículos del 38 al 41 del Reglamento de las SCE.

Así, el Organo de Dirección será responsable de la gestión de la SCE y la representará frente a terceros y ante los tribunales. El responsable de la administración corriente podrá ser un consejero delegado dispuesto por cada Estado miembro pero en las mismas condiciones establecidas para las cooperativas con domicilio en su territorio.

Otra competencia del órgano de control será nombrar y revocar a los miembros del Organo de Dirección. No obstante, según lo dispuesto en el párrafo segundo de artículo 38 de SCE se establece que «el Estado miembro podrá establecer o permitir que los estatutos dispongan que el miembro o los miembros del órgano de dirección sean nombrados o revocados por la asamblea general en las mismas condiciones que se aplican a las cooperativas domiciliadas en su territorio».

Además, los estatutos de la sociedad fijarán el número de miembros del órgano de dirección o las normas para su determinación. No 
obstante, los Estados miembros podrán establecer un número mínimo, máximo o ambos.

Para aquellos casos en los que la legislación no contemple el sistema dual en relación con las cooperativas con domicilio social en su territorio podrán adoptar las medidas oportunas en relación con las SCE, así se establece en su articulo 38.5.

La función primordial del Organo de control es la de controlar la gestión encomendada al órgano de dirección. Además sus miembros serán nombrados y destituidos por la asamblea general aunque los estatutos permiten la designación de los miembros del primer órgano de control.

Hay que destacar que no podrá ejercer por sí mismo el poder de gestión de la SCE. El órgano de control no podrá representar a la SCE ante terceros. Representará a la SCE ante el órgano de dirección o sus miembros en caso de litigio o en la celebración de contratos.

En referencia a las funciones de información el artículo 40 establece que:

«El órgano de dirección informará al órgano de control, como mínimo cada tres meses, acerca de la marcha de los asuntos de la SCE y de su evolución previsible, teniendo en cuenta cualquier información sobre las empresas controladas por la SCE que pueda influir de forma significativa en la marcha de los asuntos de esta última.»

Pero además comunicará a su debido tiempo al órgano de control cualquier información sobre hechos que puedan tener repercusiones sensibles en la situación de la SCE. Y también podrá realizar las comprobaciones necesarias para desempeñar su cometido.

\section{b) CONVOCATORIA}

El presidente del Organo de Dirección, es el encargado de elegido de entre sus miembros, será quien convoque al órgano. La convocatoria puede hacerse:

- por iniciativa propia o

— por petición de cualquiera de sus miembros.

Si la petición no es atendida en un plazo de quince días, el Organo de Dirección podrá ser convocado por el miembro o miembros que lo formularon. Además, deberán constar los motivos de la convocatoria. 


\subsection{Sistema monista: Organo de Administración}

a) FUNCIONES Y DESIGNACIÓN DE SUS MIEMBROS

La competencia de este órgano, será la de asumir la gestión de la SCE y la representará frente a terceros y ante los tribunales.

El responsable de la administración corriente puede ser un consejero delegado en las mismas condiciones establecidas para las cooperativas con domicilio en su territorio. Sin embargo, el número de miembros del órgano de administración o las normas serán determinadas en cada caso por los estatutos de la SCE.

Pero no podemos olvidar que los Estados miembros cuya legislación no contemple el sistema monista en relación con las cooperativas con domicilio social en su territorio deberán adoptar las medidas oportunas en relación con las SCE.

\section{b) Periodicidad de las Reuniones y derecho a la información}

La convocatoria del órgano de administración será como mínimo cada tres meses, aunque los estatutos pueden fijar otra periodicidad, para deliberar acerca de la marcha de los asuntos de la SCE y de su evolución previsible, teniendo en cuenta, en su caso, cualquier información sobre las empresas controladas por la SCE que puedan influir de forma significativa en la marcha de los asuntos de esta última (artículo 43 SCE)

Cada miembro del órgano de administración tendrá acceso a todos los informes, documentos e información comunicados a dicho órgano.

\section{c) Presidencia y convocatoria del Organo de Administración}

El órgano de administración tendrá un presidente, que elegido de entre sus miembros, convocará al órgano de administración en las condiciones que fijen los estatutos:

- bien por iniciativa propia

- bien a petición de al menos un tercio de sus miembros.

En la petición se deberán indicar los motivos de la convocatoria. Si la petición no es atendida en un plazo de quince días, el órgano de administración podrá ser convocado por quienes la formularon. Es de- 
cir, sigue el mismo procedimiento que el órgano de dirección y el órgano de control.

\subsection{Normas comunes a los sistemas monista y dual (artículos del 45 al 51 SCE)}

Existen diferentes normas comunes para regular las condiciones de nombramiento, elegibilidad, entre otras, que se encuentran recogidas en los artículos del 45 al 51 SCE. Así queda establecido que los miembros de los órganos de la SCE serán nombrados por un período establecido en los estatutos, que no podrá exceder de seis años.

Además también se tendrá en cuenta el artículo 46 SCE que dispone lo siguiente:

«1. Los estatutos de la SCE podrán establecer que una sociedad en el sentido del artículo 48 del Tratado pueda ser miembro de uno de sus órganos, excepto cuando la legislación aplicable a las cooperativas del Estado miembro donde esté domiciliada la SCE disponga lo contrario.

Dicha sociedad deberá designar a una persona física como representante para el ejercicio de sus funciones en el órgano de que se trate. El representante estará sometido a las mismas condiciones y obligaciones que si fuera miembro de este órgano a título personal.

2. No podrán ser miembros de ninguno de los órganos de la SCE, ni representantes de un miembro en el sentido del apartado 1, las personas que:

- de acuerdo con la legislación del Estado miembro del domicilio social de la SCE, no puedan formar parte del órgano correspondiente de una cooperativa constituida con arreglo al Derecho de dicho Estado miembro; o

- no puedan formar parte del órgano correspondiente de una cooperativa constituida con arreglo al Derecho de un Estado miembro en virtud de resolución judicial o administrativa dictada en un Estado miembro.

3. De conformidad con la legislación del Estado miembro con respecto a las cooperativas, los estatutos de la SCE podrán fijar condiciones particulares para poder ser elegido miembro del órgano de administración.»

Sin embargo, los estatutos pueden establecer casos de restricciones, así los miembros podrán ser nombrados nuevamente una o más veces por el periodo de 6 años. 
En el caso del poder de representación y responsabilidad la SCE en su artículo 47 se establece que:

«1. Cuando, con arreglo al apartado 1 del artículo 37 y al apartado 1 del artículo 42, el ejercicio del poder de representación de la SCE frente a terceros se confíe a más de un miembro, dichos miembros ejercerán ese poder colectivamente, salvo que el Derecho del Estado miembro del domicilio social de la SCE permita que los estatutos dispongan otra cosa, en cuyo caso esta cláusula será oponible frente a terceros cuando sea objeto de la publicidad a que se refieren el apartado 5 del artículo 11 y el artículo 12.

2. La SCE quedará obligada frente a terceros por los actos realizados por sus órganos, aun cuando tales actos no se correspondan con el objeto social de esta sociedad, a menos que dichos actos constituyan una extralimitación de los poderes que la legislación del Estado miembro del domicilio social de la SCE confiere o permite conferir a dichos órganos.

No obstante, los Estados miembros podrán establecer que la SCE no quede obligada cuando tales actos sobrepasen los límites del objeto social de la SCE, si ésta prueba que el tercero sabía que el acto sobrepasaba dicho objeto o, habida cuenta de las circunstancias, no podía ignorarlo, quedando entendido que la publicación de los estatutos no constituirá, por sí sola, una prueba.

3. Las limitaciones a los poderes de los órganos de la SCE resultantes de los estatutos o de una decisión de los órganos competentes no se podrán oponer en ningún caso frente a terceros, aunque se hayan publicado.

4. Los Estados miembros podrán estipular que el poder de representación de la SCE pueda ser atribuido por disposición estatutaria a una sola persona o a varias personas que actúen conjuntamente. Dicha legislación podrá establecer la oponibilidad frente a terceros de esta disposición de los estatutos, a condición de que ésta se refiera al poder general de representación. La oponibilidad frente a terceros de dicha disposición se regirá por lo dispuesto en el artículo 12.»

Para finalizar, las decisiones de los órganos salvo en los casos en que el Reglamento o los estatutos dispongan otra cosa, las normas internas relativas al quórum y a la toma de decisiones de los órganos de la SCE serán las siguientes:

a) Quórum: Al menos la mitad de los miembros con derecho de voto deberán estar presentes o representados. 
b) Toma de decisiones: Se hará por mayoría de los miembros con derecho de voto presentes o representados.

Los miembros ausentes podrán participar en los acuerdos dando un poder de representación a otro miembro del órgano o a los suplentes que hayan sido designados al mismo tiempo para representarlos.

A falta de disposición estatutaria al respecto, el presidente de cada órgano tendrá voto de calidad en caso de empate. No obstante, no podrá existir ninguna disposición estatuaria en sentido contrario cuando la mitad del órgano de control esté compuesta por representantes de los trabajadores.

En lo que se refiere a la responsabilidad civil los miembros del órgano de dirección, de control o de administración responderán, según las disposiciones aplicables a las cooperativas del Estado miembro donde esté domiciliada la SCE, del perjuicio sufrido por la SCE debido al incumplimiento por parte de éstos de las obligaciones legales, estatutarias o de cualquier otro tipo inherentes a sus funciones.

\section{F) CONCLUSION}

Para poder conseguir en una empresa lo que se denomina «Buen Gobierno», es necesario remitirse a lo que la Comisión de la Unión Europea entiende por esta expresión.

Así, se entiende por ello el cómo motivar a los gestores, la relación entre accionistas y socios, la asunción de la relación entre los gestores, lo referente a la ética y la responsabilidad de la empresa en el ejercicio de sus funciones.

En conclusión, el «Buen Gobierno» es la forma en la que las empresas se dirigen y se controlan. Lo que exige es un sistema eficaz y transparente y para ello es necesario que las empresas se compongan de unos órganos de administración y control (Asamblea General y Consejo Rector) para que se obtenga eficacia empresarial y, en definitiva, calidad en el funcionamiento de la empresa.

Las Sociedades Cooperativas son compañías democráticas en las que prima la sociedad sobre el capital. Son sociedades en las que los socios deben asegurar unos mínimos de seguridad de la compañía en base a valores de honestidad y eficacia de su gestión, para lo que 
hace falta proveerse un buen gobierno dentro de la empresa. Para ver qué sistema es necesario seguir para alcanzar un buen sistema de gobierno lo que puede hacer la Administración para ello es hacer un análisis de comparación entre el orden internacional y el ámbito cooperativo vasco. El consejo Rector, por ello, es fundamental dentro de la cooperativa y debe atender por ello las siguientes cuestiones:

\section{- La Dirección Adecuada:}

Debe reunir las condiciones y las características necesarias para poder adoptar una actitud «valiente» con el fin de defender o, en su caso, sustituir al gerente, por lo que adopta una posición activa en el proceso de selección y evaluación de cómo desarrolla éste su actividad.

\section{- Ambito de trabajo del Gerente:}

Tiene capacidad operativa y es necesario para canalizar los conflictos entre los grupos de socios. Su control no implica intromisión en otros temas.

\section{- Supervisión estratégica:}

Es necesario invertir en formación para prever a la empresa de un supervisor estratégico, ya que es un instrumento muy eficaz para asegurar la veracidad de la información y concretar los criterios a través de los que se va a participar.

\section{- Número de consejeros:}

Es un factor ambiguo que se deberá atender para cada sociedad en cada caso. El factor representatividad lleva al aumento del número de miembros. El factor eficacia lleva a la disminución del número de miembros.

\section{- Consejo ideal:}

El requisito fundamental que debe reunir es el de tener capacidad para ser eficaz a largo plazo, sin olvidar, para poder obtener tal resultado, los factores de información e independencia.

En la sociedad cooperativa no existe únicamente la institución del Consejo, que se encarga del control de la gestión y mediante lo que todo socio tiene derecho a solicitar todo tipo de información que le afecte personalmente; sino que, a su vez, existe otro órgano específico dedicado al control sobre la actuación de los administradores que 
es la Comisión de Vigilancia, que coopera junto con el Consejo a que la consecución de un «Buen Gobierno» se haga posible.

Debido a la entrada de España en la Unión Europea y a la globalización, se ha creado, a su vez, un Estatuto Europeo de Cooperativas que anuncia la doble estructura que pretende el mercado único.

En su exposición introductoria se expone claramente que la misión del Estatuto es facilitar el desarrollo de actividades transfronterizas de las cooperativas.

Asimismo, insta a establecer a todos los Estados miembros una legislación de cooperativas en situaciones iguales para llevar adelante el sistema democrático económico.

Pero ni la legislación cooperativa en el ámbito nacional, ni la actual masificación en todos los órdenes del factor de globalización, pueden hacer que se olvide en las legislaciones del factor primordial que hace que la labor de la cooperativa sea posible, esto es: el SOCIO.

El socio es un elemento clave en la sociedad cooperativa ya que participa en el gobierno de la compañía. Tal sujeto debe ser capaz de actuar con rapidez, eficacia y trasparencia en situaciones de crisis, por lo que el interés del socio es fundamental en el gobierno de la cooperativa.

Hay determinadas cooperativas en las que números determinados de socios participan en otras empresas, no involucrándose así de lleno en la compañía, lo que puede generar problemas en el gobierno cooperativo.

Así, a más número de socios, menos participación. Por eso hay que tratar de configurar las cooperativas en base a unos intereses homogéneos, introduciendo mecanismos de organización y creando cooperativas distintas con intereses diversos. El problema radica en la no coincidencia posible entre el interés individual del socio y el interés colectivo de la sociedad.

Finalmente, y debido a lo expuesto, para el caso de una posible modificación de los órganos de gobierno de las sociedades cooperativas, habría que atender, no únicamente en los órganos de la compañía, sino centrarse con el mismo rigor en el elemento subjetivo de la misma, en el socio, ya que si bien aquéllos son de suma importancia, es éste el motor que hace posible que la sociedad funcione con firmeza, calidad y eficacia. 


\section{Bibliografía}

Ley de Cooperativas de Euskadi (de 24 de junio de 1993).

Ley de Cooperativas (de 16 de julio de 1999).

Estatuto de la Sociedad Cooperativa Europea.

«Análisis de la Legislación Vasca sobre Cooperativas» (J. Larrañaga / Caja Laboral / País Vasco) Editorial Caja Laboral Popular.

Gran + Enciclopedia Larousse.

Apuntes de clase (curso 2003 - 2004).

Apuntes basados en el Simposio sobre la Cultura Económica Vasca: el Buen Gobierno de las Cooperativas. 